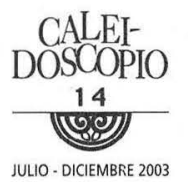

\title{
UNA MIRADA AL DERECHO DESDE LA BIBLIA
}

JESÚS ANTONIO DE LA TORRE RANGEL

Departamento de Derecho/UAA

Alejandro Rosillo Martínez, Que fluya la justicia. Justicia y derechos humanos en los textos bíblicos: una lectura jurídica, Facultad de Derecho de la Universidad Autónoma de San Luis Potosí, Comisión de Derechos Humanos del Estado de San Luis Potosí y Centro de Reflexión Teológica, A. C., 2003, 237 pp.

$\mathrm{H}$ ace algunos días leí unas reflexiones muy interesantes del padre Alberto Hurtado, jesuita chileno del siglo XX, cuya causa de canonización está abierta. Decía:

Muchas obras de caridad pueden ser ostentadas por nuestra sociedad, pero todo este inmenso esfuerzo de generosidad, muy de alabar, no logra reparar los estragos de la injusticia. La injusticia causa enormemente más males que los que puede reparar la caridad $[\ldots]$ lo que las personas no están dispuestas a seguir tolerando es que se les niegue la justicia y se les otorgue con aparente misericordia en nombre de la caridad lo que les corresponde por derecho. ${ }^{1}$

Las teorías jurídicas modernas, quiero decir aquellas que hunden sus raíces en el pensamiento de la modernidad, dividieron tajantemente el ámbito de competencia, en el pensar y en el actuar, del Derecho y de la Ética, dejando al primero la normatividad que proviene del Estado y a la segunda las acciones dictadas por la conciencia individual. La justicia, como cuestión ética fundamental, quedó desplazada de la teoría y

Mensaje, núm. 521, Santiago de Chile, agosto de 2003. 
de la acción jurídicas y, por lo tanto, sociales. Así que si las leyes y las políticas de Estado no pueden subsanar los males sociales, quedan las acciones "caritativas", aunque mejor llamarlas de limosna, producto de una ética laica o religiosa, como remedio. Recurso insuficiente, pues de justicia se trata.

Urge sacar a la justicia del ámbito de la conciencia ética individual y hacer una reflexión seria sobre esta virtud social y llevarla al Derecho como el lugar que le corresponde y del cual nunca debió salir.

Por eso me da mucho gusto presentar este libro del joven jurista Alejandro Rosillo Martínez que, inspirándose en el profeta Amós, lo titula: Que fluya la justicia, en el que intenta, con éxito, una lectura jurídica de la Biblia, destacando sus aspectos sobre la justicia y los derechos humanos.

Es un libro muy extraño para los tiempos que corren, pues se trata de una obra teológicojurídica. Rosillo Martínez inscribe su texto y su quehacer teórico en la vieja tradición de los teólogos juristas que se desarrolló en la Edad Media y a principios de la Modernidad como una reflexión sobre el Derecho desde los presupuestos de la fe cristiana.
Esta tradición teórica es muy rica, baste citar algunos de sus cultivadores como los teólogos juristas medievales San Braulio (+650), obispo de Zaragoza y San Isidoro de Sevilla (562-636) y los grandes teólogos juristas del siglo XVI español, como los miembros de la Escuela de Salamanca, entre los cuales destacan los dominicos: Francisco de Vitoria (14831546) y Domingo de Soto (1495. 1560); los jesuitas: Luis de Molina (1535-1600), Juan de Mariana (1536-1624) y Francisco Suárez (1548-1617); sin olvidar a nuestros teólogos juristas novohispanos, defensores de los derechos humanos de los indios inspirados en el Evangelio: Bartolomé de Las Casas (1474 1566), Alonso de la Veracruz (1507-1584) y Vásco de Quiroga (1470-1565). Que fluya la justicia es, entonces, una obra de un teólogo jurista en los albores del siglo XXI. Bienvenido sea este libro que hacía falta.

La temática abordada por Rosillo había sido tratada desde el punto de vista teológico, en tiempos recientes, por autores como el peruano Hugo Echegaray, el mexicano Porfirio Miranda y los jesuitas, profesores de la Universidad Centroamericana de San Salvador; el mártir intelectual 
luchador por los derechos humanos, Ignacio Ellacuría y el estupendo teólogo, Jon Sobrino. Por mi parte, he trabajado también el tema pero desde la Filosofía del Derecho, esto es utilizando el sentido profundo del Derecho de acuerdo a la tradición bíblica, pero como categoría filosófica, no haciendo teología sino filosofía. Rosillo Martínez, en cambio, hace teología-jurídica en este libro; no se queda sólo en el ámbito filosófico sino que agrega a la reflexión teológica la visión del jurista, del abogado.

Alejandro Rosillo pretende, entonces, añadir a la reflexión filosófico jurídica, que dice «ilumina la praxis humana» como contribución para que el Derecho positivo se enderece a hacer efectiva la justicia y el respeto y promoción de los derechos humanos, pretende añadirle, decimos, la teología que "ilumina la praxis humana a partir de la fe cristiana", como un quehacer teórico con relación a la justicia y los derechos humanos, buscando desde esa óptica, también, una contribución a su efectividad real, histórica.

Bienvenido, reiteramos, sea el libro de Alejandro Rosillo, al mundo del Derecho, al ámbito de la teoría jurídica.
El mundo moderno y postmoderno no sólo individualizó la ética sino que ha perdido el sentido de lo sacro; se ha organizado sin saber mirar la presencia misteriosa de Dios en los seres humanos y en todo lo que nos rodea y con lo que coexistimos. La técnica se ha erigido en el lugar de Dios en la sociedad económica. La tecnificación ha invadido todo; el mismo Derecho ha sido reducido a la técnica; técnica, en el mejor de los casos, para regular relaciones entre personas, y en el peor -no poco frecuente-, como técnica de dominación política y económica de las mayorías. El Derecho no se enseña, no se piensa y no se ejercita, en su sentido más profundo de servicio a las personas como respeto de sus derechos y cumplimiento de la justicia. Dice Iván Illich que somos herederos de Newton, sólo atendemos a la causa eficiente de las cosas: "[...] la idea de una Causa Final primera o primigenia, una razón última $[\ldots]$ es completamente ajena a nuestro siglo". ${ }^{2}$ Y esto tiene también que

Iván Illich, El Viñedo del Texto, México, Fondo de Cultura Económica, 2002. 
ver con el Derecho; se busca su eficiencia, no su justicia.

El libro de Rosillo es muy importante porque antepone a la técnica del Derecho los aspectos más humanos de lo jurídico, esto es la justicia y los derechos de las personas como sujetos individuales y colectivos. Y enraiza el Derecho en lo sagrado, esto es en un plan de Dios que está por la justicia que implica la restauración de sus derechos en aquellos que han sido despojados de los mismos; esto, a final de cuentas, porque el ser humano, varón y mujer, son imagen y semejanza de Dios, y los que han sido empobrecidos en sus derechos, los pobres, constituyen la epifanía de Dios en la historia, de acuerdo a las enseñanzas de Jesús y son reclamantes de las condiciones materiales que hagan posible su vida digna.

Rosillo Martínez, para elaborar su obra, opta por una escuela teológica que "como consecuencia de sus planteamientos y su metodología, sus resultados aporten elementos valiosos acerca de la justicia y los derechos humanos", y ésta es la llamada teología de la liberación. El autor nos recuerda que el teólogo peruano Gustavo Gutiérrez fue el primero en denominar así a esta corriente teológica, a principios de los años setentas del siglo XX. Pues es de Gustavo Gutiérrez de quien tomamos las siguientes reflexiones publicadas recientemente. Al estar tratando de la injusticia que padecen actualmente los pobres en este mundo globalizado de economía neoliberal, Gutiérrez escribe: "Esta situación, tal como la conocemos actualmente, con su carga de muerte injusta y prematura, lanza un cuestionamiento radical y englobante a la conciencia humana y a la manera de aproximarse a la fe cristiana". ${ }^{3}$

Y agrega el teólogo peruano que esto configura un "campo hermenéutico" que nos conduce a una relectura del mensaje bíblico y del camino a emprender como discípulos de Jesús. Lo que significa que está proponiendo como clave de interpretación de la Biblia y de la espiritualidad y prácticas cristianas, la "muerte injusta y prematura" de los pobres.

En todo el libro de Rosillo encuentro implícito y a veces explícito el "campo hermenéu-

Páginas, núm. 177, Lima, octubre de 2002. 
tico" que propone Gustavo Gutiérrez, pues su visión interpretativa del mensaje cristiano y del Derecho es precisamente la "muerte injusta y prematura" de los pobres, porque esta realidad niega precisamente la vigencia efectiva de los derechos humanos, ya que no existen las posibilidades y condiciones de vida digna para todos, lo que origina precisamente la muerte. Este "campo hermenéutico" debiera siempre incorporarse a la interpretación del Derecho; lo jurídico se vería de forma distinta. Los abogados y operadores jurídicos miraríamos de otro modo.

Y ¿cómo tratar de evitar esa "muerte injusta y prematura" de los pobres contribuyendo desde el campo del Derecho? Rosillo nos propone, entre otras cosas, lo que llama "claves importantes para una visión de los derechos humanos" desde la parábola de El buen samaritano ${ }^{4}$. Entre ellas se destaca que, ante las necesidades del moribundo, existe la compasión de quien lo ayuda, que lo lleva a tratar de poner remedio íntegramente a sus padecimientos. Al final de cuentas son acciones de justicia -restablecimiento de sus condiciones de vida-, por amor al prójimo.

La solución que nos ofrece Rosillo, a fuer de fidelidad al mensaje cristiano, es la misma a la que llegan los clásicos teólogos juristas. Así Isidoro de Sevilla en sus Sentencias establecía que en los asuntos del foro debía prevalecer, sobre todo, la caridad del prójimo; y nuestro Alonso de la Veracruz sostenía que los juicios no deben funcionar contra la caridad y la justicia. ${ }^{5}$ Y éste es el sentido más profundo del Derecho, para aquellos que creemos que Dios habla por los profetas y se revela plenamente en las palabras y en la praxis de Jesús. Aquí, caridad se entiende como amor al prójimo y viene a completar a la justicia concreta; no es la limosna que pretende sustituir a la justicia. Que bueno que el libro de Alejandro Rosillo nos lo recuerde a los abogados y a los teóricos del Derecho.

. 
